\title{
The Transformation and Development of Hotel under the Background of Pension
}

\section{Industry}

\author{
Xia Xu \\ Ginlin Tourism University, Guilin City, Guangxi Province, 541006, China
}

Keywords: pension industry; aging of population; hotel; transformation; development

\begin{abstract}
The difficulties and challenges brought by the rapid aging of population is obvious, but also brought some enterprises opportunities for development and the hotel industry is one of them. Base on the study and practice experiences of the author, this paper analyzed the transformation of hotel under the background of aging of population from tradition hotel to pension hotel. This paper firstly analyzed the concept and significance of pension hotel, and then discussed the development opportunities of China's pension hotel, finally put forward some countermeasures of the transformation of pension hotel from tradition hotel.
\end{abstract}

\section{Introduction}

According to 2013 social service development statistical bulletin promulgated by Ministry of Civil Affairs, up to 2013, the number of the population of 60 years old and older in China has exceeded 200 million. As the arrival of the aging society, China's family pattern has got a sharp shift. The traditional family pattern that several generations live together is turning into the small family pattern that young people live apart from old people, resulting in a large number of "empty nest family". The lack of facilities for the elderly family makes the traditional pattern of home-based care for the aged has been difficult to adapt the needs of the aging of population. At the same time, a serious shortage of social supporting resource for elderly makes the elderly stay in the plight of "unable to enjoy in old age at home, but also nowhere to go in the outside". This is a common problem in China for a long time in the future and it will be increasingly serious.

\section{The Concept and Significance of Pension Hotel}

The overview of pension hotel. Pension hotel puts meeting the needs of the elderly health care above everything else. On the basis of providing high quality living environments for residents, match with medical care, cultural entertainment, life care, rehabilitation and other one-stop comprehensive hotel. Pension hotel is a new pattern of hotel industry that adapts to the current social pension needs, it creatively combines the management service concept of starred hotel and pension functions together organically, so that the elderly live in an favorable environment in the hotel apartment like at home.

The significance of developing pension hotel. To develop pension hotel can remit the contradiction between supply and demand of pension services. In recent years, in order to cope with the increasingly serious situation of aging of population.aging population, the Chinese governments at all levels plan the construction of pension service system in full sail and the development of pension services is rapid, and it has initially built a pension service system which is based on home, relies on community and supported by service agencies. But overall, the problem of the shortage of pension services product supply is still very prominent. Developing pension hotel is an important measure to make up for the lack of pension institutions, it can meet the needs of some elderly people who have higher needs as well as remit the increasingly serious contradiction between supply and demand of pension services. Meanwhile, it is also helpful for stimulating consumption, enlarging employment and promoting the sound and continuous development of economic society. 


\section{The Development Opportunity of Chinese Pension Hotel}

The government provides policy orientation. As the development of social economy, in recent years, the degree of recognition of Chinese governments at all levels to the problem of aging has been strengthened constantly.In September 2013, the State Council put forward in Several Suggestions about Accelerating the Development of Pension Service Industry: China will lower the threshold of social forces hold pension agencies, encourage foreign capital investment in the pension service industry, encourage individuals to hold the pension institutions of the pattern of family and miniaturization, encourage social forces hold large-scale and chain-orientation institutions and encourage private capitals integrate and transform the work shops of enterprises, commercial facilities and other social resources which is available; and provide policy supports to the investment and financing, land supply, tax concessions, subsidies support, talent training and employment, etc, in order to encourage and guide the related industries and actively expand the services that fit to the characteristic of elderly, such as cultural entertainment, physical fitness, leisure tourism, health services, spiritual consolation and legal services, etc. The Twelfth Five-year Development Plan of Aging Industry in JiangSu Province proposed that we should provide major supports to the nursing type pension services which are invested by the society and make efforts to form a pension service institution system which including top, middle and low grades, and the functions of supporting, nursing and helping as well as several management styles develop together. Shanghai made clear in the 12th Five-Year plan, we should encourage and support the private capital to participate in the pension services, and attract social forces to construct elderly apartments, leisure pension bases and other pension facilities.

The growing elderly consumer group provides a broad market. As the change of people's life concept, the number of the old people who are willing to choose "pension institutions"tends to increase. Above all, the "421" family pattern makes "home-based care for the aged" become unpractical, and the fierce social competition and frequent occupation flow makes a lot of children lack of time and vigor to care their parents, so the ability of family pension is lower. Secondly, the resources of social are scarce, and the government's welfare pension institutions have many restrictions on the old people who will live into there, so the imbalance between supply and demand of pension resources is worsen. Finally, the elderly concept changes continually, a considerable part of the old people who have fixed income have the ability and willingness to stay in high quality pension institutions. Make a general survey of Chinese pension agencies, many of them is improving and upgrading, in order to develop to the high-quality direction. Thus, the growing elderly consumer groups provide pension hotels a broad market.

The management and administration of Starred-hotels provide hotel experiences. The hotel industry in China after 30 years of development after the reform and opening-up policy, have made obvious achievements on the concepts of management, hardware facilities, service levels and other aspects. As the implementation of the new assessment standards of starred-hotels in 2010, the strict assessment standards promotes the whole service quality of hotel industry continuously improve. The services provided by all departments of hotels are similar to the basic functions of the related departments of pension institutions, which provides referential experiences for the development of pension hotels.

\section{The Countermeasure of Transformation of Tradition Hotel to the Pension Hotel}

The locations and environments of pension hotels. The locations of pension hotels should be selected in suburbs where away from blatant towns and have fresh air, beautiful environment and convenient traffic. These hotels should make effort to build humanized elderly living environments that are natural, healthy, stately and happy from the functional zones, park landscapes, infrastructure systems and other aspects. Such as China's first pension hotel - JiuHua International Health Care Organization that located in Xiaotangshan, in the western suburbs of Beijing. It has a beautiful environment and provides a comfortable living environment for the elderly. 
Comfortable accommodation, catering and entertainment facilities. First, accommodation facilities. The pension hotels' facilities and service standards are relatively high and need to give residents high-quality life experiences like at home. The constructions and decorations should use environmental and high-quality brand material.The design concepts of interior decorations are advanced and collocate applicable whole set of household appliances and furniture, that means the old people can live into there only with their own bags. Hotels build large-sized suites according to the guest family structures, so that the old people's wishes that they want to live with their family together can be realized or their family are convenience to visit them. The way can not only meet the needs of old people's pension care, but also let them get the comforts from their family. These hotels should be equipped with internal medical elevators and collocate health monitoring equipment that links to proper medical centers. The bathrooms should have enough spaces so that wheelchairs can be used indoor normally, and all of passageways as well as bathrooms are collocated with necessary assistant support facilities. The indoor floors should be lay with ship-and-galley tiles, and if possible, using geothermal heating according to the climate conditions.

Second, catering facilities. For the elderly, catering problem is the most urgent problem that they need to solve. Due to the decrease of digestive function, cardiovascular system and other organs have different degrees of degradation, and the elderly especially the advanced ages, valetudinarian and inconvenience old people, urgently need the restaurants that have professional nutritionists who can provide convenient and rapid nutrient food services. The restaurants of pension hotels should be located in the bottom buildings near the entrances of the hotels, and adopt open and connected arrangements and have large spaces, so that the elderly can get together and communicate conveniently and the hotels also can be open to non-residents. According to the scale of development and the needs of customers, set up a number of rooms to meet the old people's family gatherings, banquets and other needs. The restaurants should be equipped with professional nutritionists and direct at the elderly health and hobbies develop the menus, and select the green foods are "low level of sugar or fat, nutrient and easy to digest", and according to the seasonal changes and provide herbal cuisine, herbal tea as well as herbal wine, etc. They should ensure the foods are safe and healthy.

Third, pension hotels should match the complete facilities of sports recreation centers and cultural entertainment centers, such as gyms, reading rooms, functional rooms and chess rooms, etc. Relying on the related facilities, regularly carry out a variety of sports activities that are suitable for the old people and meet their needs of entertainment and social culture. In addition to the restaurants, supermarkets and other basic living facilities, the hotels should also have small shopping centers and other commercial facilities, such as clothes, foods and drug stores for old people as well as nostalgic theme tea houses or coffee shops that are favored by old people.

Scientific and thorough medical equipment. Compared with the current social pension institutions, pension hotels should commit to provide thorough medical rehabilitation facilities that includes physical examination, rehabilitation, health care and medical treatment. The specifics include: firstly, it is the elderly health assessment and guidance center that equipped with advanced medical equipment and built the team of health consultant, in order to provide free regular physical examination, health evaluation and archives management, health counseling and other services. Secondly, it is the maintenance center that equipped with physical therapy room, spa room and psychological therapeutic room, etc, and have professional nursing team with qualification and experience. Relying on the maintenance center, the hotels can provide the services of rehabilitation physiotherapy and nursing maintenance after diseases. In addition, the hotels can cooperate with the relevant hospitals and open convenient channels for medical treatments, or establish geriatrics rooms in the hotels for the elderly, and provide medical services to guests. If possible, part of the hotels can also build their own hospital for the elderly, and take the geriatrics as a research focus and make a medical team that are built with the experts of cardiovascular and cerebrovascular diseases, cancer and other fields. The team can provide treatments, emergency ambulance services for the guests. A thorough health medical system is one of important standard of measure a pension hotel, and through establish health assessment and guidance center, maintenance center and the hospital for the elderly, 
and really provide them a thorough health medical security from physical examination to rehabilitation and connect with health insurance and solve the worries of them.

\section{Summary}

The rapid aging of population brings the government and society serious challenges, and has a profound influence on the development of Chinese hotel industry. The growing elderly consumer groups and the policy support of all levels of government provide opportunities for the pension hotel industry's development. But we have to admit that Chinese pension hotels are facing the restricts of the market has not yet fully formed and the shortage of the talent of service and management, and other factors. Therefore, as long as the tradition hotel industry conform to the "silver hair trend" and embrace the "cake" of the elderly market that needs to be developed, and gradually change the traditional business pattern as well as make innovation of commercial activities of pension hotels, it can be show itself in the fierce competition between industries.

\section{Acknowledgement}

Project fund: High level innovation team in Guangxi institutions of higher learning(breeding unit).

\section{References}

[1] He Chang. How difficult the hotel transforms into pension hotel? [J]. home service, 2017, (02): 22-23.

[2] Dan Dan. "Starred" pension pattern marches into the "silver hair industry" [J]. labor security world, 2014, (12): 55

[3] Ma Jian. The training of the aged talents should be combined with inside and outside [J]. family service, 2016, (07): 28-29.

[4] He Yun. The discussion on the development of the pension hotel in China [J]. Journal of Jiangsu Institute of Economic\&Trade Technology, 2014, (06): 40-43.

[5] Wang Qi, Zhang Shuifang. Preliminary study on the integration of privately operated hotel industry and pension service industry in Zhejiang province[J]. Journal of Hubei Correspondence University, 2015,(18): 76-77+102.

[6] Zhang Jianqing. Problems and Countermeasures of transforming of privately operated hotel into pension institutions in Ningbo[J]. Journal of Ningbo University of Technology, 2015, (03): 84-88. 